\title{
Quality Control Assessment \& Comparisons with the USA Standard Values
}

\author{
Murad Alsawalha ${ }^{1}$, Mohammed El-Zagheid ${ }^{2}$ \\ ${ }^{1}$ Department of Chemical and Process Engineering Technology, Jubail Industrial College \\ P.O. Box 10099, Jubail Industrial City- 31961, Saudi Arabia
}

\begin{abstract}
This article aimed to generate out a quality control assessment of the performed analytical analysis, to highlight the importance of delivering quality control system independent of how these calculations are limited. Therefore, different commercial milk powder samples were analyzed for their fat, moisture and ash, and then the standard deviations were calculated, accordingly. Repeatability and reproducibility of the analysis show good results, and the comparability of the achieved results with the USA standard values presented likewise a very close acceptance range.
\end{abstract}

Keywords-Milk powder, Milk fat, Quality Control, Standard Specifications

\section{INTRODUCTION}

Milk is one kind of essential nutriments in our daily life and widely used. They are easily transported and stored. The changing of the main components such as lactose, protein and fat may cause deterioration of milk powders if the storage conditions are improper. Lactose crystallization in milk powders has mainly aroused due to storage time, lactose glass transition (physical state) and water content [1-3].

Milk fat and Lactose, are a ready source of dietary energy. Milk producers were paid a premium for the milk fat content of the milk they produced. The primary elements in milk powders are linked to each other. Usually, fat (or lipid) makes up from 3.5 to $6.0 \%$ of milk content, varying between breeds of cattle and with feeding practices [4]. Fat is present in milk in small globules suspended in water. Each globule is surrounded by a layer of phospholipids, which prevents the globules from clumping together by repelling other fat globules and attracting water. As long as this structure is intact, the milk fat remains as an emulsion. The majority of milk fat is in the form of triglycerides formed by the linking of glycerol and fatty acids. The fat content and fatty acid composition of milk can be dramatically affected by dietary manipulation in many species [5]. In the past, two methods were published for the determination of lactose in milk. By means of which we were capable to find out the carbohydrate content in milk rapidly, and with a considerable degree of accuracy. Hence, quality control assessment tools are important in guiding milk collectors, central processing units and marketing agencies to follow the right methods. Having a good system, will benefit everyone involved in the dairy industry.

The impact of quality control along with the chemical analysis was also discussed in the literature [6]. Mohsen [7] studied another example for the importance of quality control in chemical analysis by detecting Iodine in milk. The detection limits of Iodine not affected by interfering from milk gradient and the minimum detection limit (MDL) of Iodine approach $10 \mathrm{ppm}$ and, the accuracy of the method ranged from 95 to $100 \%$.

\section{Sampling}

\section{MATERIALS AND METHODS}

Different full fat milk commercial powder samples were purchased from different supermarkets and analyzed for determination of lactose and fat contents. More often than not, there is no need to examine the whole measure of milk; we can examine only a small sample to determine the quality. Accurate sampling, however, is indispensable for a proper quality control testing system. Liquid milk in cans and bulk tanks should be thoroughly mixed to disperse the milk fat. In the case of packed products like our case, representative samples were be taken to make sure that the samples are actually reflecting the whole batch.

\section{Principle determination of fat content in milk powder}

A clean and dry butyrometer was put in a butyrometer stand with an open mouth upwards. A $9 \mathrm{ml}$ of sulfuric acid with the tilt measure was run in the butyrometer. Pipette out $10.8 \mathrm{ml}$ of milk $(5 \mathrm{~g}$ powder milk dissolved in warm water) sample gently by the side of butyrometer. Pour one ml. of amyl alcohol with tilt measure. The tube is well (mixed) shaken until mahogany red color obtained. Keep the butyrometer in hot water bath until it attains $17^{\circ} \mathrm{C}$ and the butyrometer then placed in the centrifuged machine that revolved at 
1100 RPM for 4 minutes. The butyrometer was taken in an upright position with the stopper end downwards and, kept in hot water bath $\left(60^{\circ} \mathrm{C}\right)$ for thirty minutes.

\section{RESULTS AND DISCUSSION}

pH

The $\mathrm{pH}$ content and $\mathrm{pH}$ of the reconstitute milk powder obtained were $6.52 \pm 0.06,6.4 \pm 0.20,6.73 \pm 0.08$, $6.4 \pm 0.1,6.5 \pm 0.00,6.57 \pm 0.04$, respectively. Statistically, there were no substantial conflicts within the $\mathrm{pH}$ of different cases of milk powder collected from local market.

\section{Determination of fat content of Gerber method \\ - Repeatability}

The precision determines the consistency, or repeatability, of analytical measurements. Testing standard solutions may help in the advance of precision and accuracy of chemical analyses. The obtained difference between two determinations carried out simultaneously by the same operator and under the same conditions within a short interval of time did not exceed a value comparable to one smallest scale division $(0.5 \%)$.

\section{- Reproducibility}

The absolute difference between two single test results, obtained by different laboratory using different equipment, didn't exceed a value corresponding to one scale division $(0.5 \%)$.

\section{- Uncertainty}

The uncertainty is based on standard uncertainty multiplied by a coverage factor $\mathrm{k}=\mathrm{two}$, providing a level of confidence of approximately $95 \%$.

\section{- Standard Deviation}

Once a sample has been analyzed, it is often helpful to determine the mean value. The mean is the sum of all values in a sample divided by the number of values included in the sum Where:

Mean, $\bar{x}=\frac{\left(x_{1}+x_{2}+x_{3}+\ldots+x_{n}\right)}{n}$

$\mathrm{x}=$ the measured value, $\mathrm{n}=$ the total number of values summed

Standard deviation estimate, $s=\sqrt{\frac{\sum\left(x_{n}-\bar{x}\right)^{2}}{n-1}}$

Standard deviation results from fifteen analyzed samples were 0.2 for the fat content, 0.02 for the moisture and 0.03 for the ash analysis.

A comparison between investigated samples with the USA standard values has been considered. It was confirmed the closeness with the USA standard values. Table 1 represents the experimental and corresponding different commercial tested samples and their comparisons with the USA standard specification values.

Table 1: Experimental and corresponding different commercial tested samples and their comparisons with the USA standard

\begin{tabular}{|l|l|l|l|}
\hline Sample & Moisture (\%) & Fat (\%) & Ash \\
\hline Almarrai & $2.25 \pm 0.02$ & $26.2 \pm 0.2$ & $5.70 \pm 0.03$ \\
\hline Nido & $2.25 \pm 0.05$ & $27.1 \pm 0.18$ & $5.69 \pm 0.03$ \\
\hline USA Standard & $<5.0$ & $26.5 \%$ & $<6.0$ \\
\hline
\end{tabular}




\section{CONCLUSION}

Performing some basic of fundamental statistic quality control calculations have its advantage to highlight and control any results' variability, independent of how these calculations limited. Therefore, local commercial samples have been examined for its moisturizing, precision (repeatability and reproducibility) and counted on its standard deviations. Moreover, the final comparison between achieving results and USA standard specifications confirmed the overall accuracy and matching acceptance range and show closeness with the international specifications.

\section{ACKNOWLEDMENT}

Authors of this article acknowledge references of this manuscript and thank JIC management for the continuous support.

\section{REFERENCES}

[1] M.E.C. Thomas, J. Scher, S. Desobry-Banon, S. Desobry, Crit. Rev. Food Sci. Nutr., 44, (5), 2004, 297

[2] K. Joupplia, Y.H. Roos,J. Sequential changes of main components in different kinds of milk powders using two-dimensional infrared correlation analysis Journal of Molecular Sturcture, 799 (1), $2006,77-84$

[3] Parry, S J, et al. The Science of the total environment 173-174, 1995, p. 351

[4] J.A. Turner, L.R. Sivasundaram, Ottenhof, I.M. Farhat, R.S.T. Linforth, A.J. Taylor, J. Agric. Food. Chem. 50 , 2002,5406

[5] P.R.Rennie,X.D.Chen,C.Hargreaves,A.R.Mackereth,J.Food. Eng. 39, 1999, 227

[6] M. Alsawalha, Quality Control Assessment for Chemical Analysis, International Journal of Science and Research. 5 (1), 2016, 946-948

[7] Mohsen B. Challan, Determination of Iodine Content in Saudi Milk Products, Journal of Natural Sciences and Mathematics, 7 (2), 2014, 101-113 